\section{Complex Formation of Platelet Thrombospondin with Plasminogen Modulation of Activation by Tissue Activator}

Roy L. Silverstein, Lawrence L. K. Leung, Peter C. Harpel, and Ralph L. Nachman

Department of Medicine, Division of Hematology-Oncology, and Specialized Center of Research in Thrombosis, The New York

Hospital-Cornell Medical Center, New York, New York 10021
A functional $\alpha$-granulet. Thrombospondin (TSP), a multifibrinogen, fibronectin, heparin, and histidine-rich glycoprotein and thus may play an important role in regulating thrombotic influences at vessel surfaces. In this study we have demonstrated that purified human platelet TSP formed a complex with purified human plasminogen ( $\mathrm{Plg})$. Complex formation was detected by rocket immunoelectrophoresis of mixtures of the purified radiolabeled proteins. Significant complex formation of fluid-phase Plg with adsorbed TSP was also demonstrated by enzyme-linked immunosorbent assay (ELISA). The complex formation was specific, saturable, and inhibited by excess fluid-phase TSP, with an apparent $K_{\mathrm{D}}$ of $\sim 35$ nM. In both ELISA and rocket immunoelectrophoresis systems, complex formation was inhibited by $10 \mathrm{mM} \epsilon$ amino- $n$-caproic acid, implying that there is a role for the lysine binding sites of Plg in mediating the interaction. TSP also formed a complex with plasmin as detected by ELISA but did not directly inhibit plasmin activity measured with a synthetic fluorometric substrate or with a ${ }^{125}$ I-fibrin plate assay. TSP, when incubated with $\mathrm{Plg}$ before addition to ${ }^{125}$ I-fibrin plates significantly inhibited the generation of plasmin activity by tissue plasminogen activator (TPA) in a manner that was calcium dependent. A kinetic study of Plg activation by TPA in the presence of TSP demonstrated that Michaelis-Menten kinetics were followed and that TSP acted as a noncompetitive inhibitor. These studies support the hypothesis that TSP,

Received for publication 1 March 1984 and in revised form 18 May 1984.

J. Clin. Invest.

(c) The American Society for Clinical Investigation, Inc. 0021-9738/84/11/1625/09 \$1.00

Volume 74, November 1984, 1625-1633 acting as a multifunctional regulator in focal areas of active hemostasis, could serve as a prothrombotic influence, leading to increased deposition of fibrin.

\section{Introduction}

Thrombospondin (TSP), ${ }^{1}$ a $450-\mathrm{kD}$ filamentous multinodular glycoprotein $(1,2)$ consisting of three $140-\mathrm{kD}$ subunits $(3)$, is a major $\alpha$-granule protein of human platelets $(4,5)$ and is expressed on the platelet surface upon thrombin stimulation (6). Although circulating plasma levels are low (20-300 ng/ ml) $(7,8)$, human fibroblasts and endothelial cells can release large amounts into their microenvironments $(9,10)$. TSP has also been identified as a synthetic product of human monocytes (11).

TSP appears to be a molecule of remarkable functional diversity. It may be important in mediating cell-to-cell communication. It is the endogenous lectin of stimulated platelets $(12,13)$. TSP binds fibrinogen (14), and monospecific antiTSP Fab' partially inhibits both platelet aggregation and platelet fibrinogen binding (15). TSP also binds collagen and fibronectin $(14,16)$ and is incorporated into the extracellular matrix of fibroblasts in culture (10). TSP may play an important role in the coagulation and fibrinolytic systems, as evidenced by its ability to form complexes with histidine-rich glycoprotein (HRGP) (17), an 80-kD plasma protein with high affinity for heparin (18), and the lysine binding sites (LBS) of plasminogen (19).

The TSP-HRGP complex in a focal area of active hemostasis and thrombosis such as the vicinity of the platelet membrane could augment thrombotic influences, leading to increased

1. Abbreviations used in this paper: AFC, 7 amino-4-trifluoromethyl coumarin; EACA, $\epsilon$-amino-n-caproic acid; ELISA, enzyme-linked immunosorbent assay; HRGP, histidine-rich glycoprotein; $I_{50}, 50 \%$ inhibitory concentration; $k_{\text {cat }}$, catalytic rate constant; LBS, lysine binding sites; Plg, plasminogen; SDS-PAGE, sodium dodecyl sulfate-polyacrylamide gel electrophoresis; TPA, tissue plasminogen activator; TSP, thrombospondin; VIIIR:Ag, Factor VIII-related antigen. 
deposition of fibrin. To define further the participation of TSP in fibrinolysis, the interaction of TSP with plasminogen (Plg) was studied. In this paper we report that TSP forms a specific complex with plasminogen and modulates its activation to plasmin by tissue plasminogen activator (TPA).

\section{Methods}

Materials. Microtitration plates for enzyme-linked immunosorbent assays (ELISA) and Linbro tissue culture plates (area, $2.0 \mathrm{~cm}^{2}$; capacity, $3.5 \mathrm{ml}$ ) for fibrin plate studies were purchased from Flow Laboratories Inc. (McLean, VA). Electrophoresis grade agarose (Seakem) was purchased from FMC Corp. (Rockland, ME). A fluorometric plasmin substrate, D-val-leu-lys-7 amino-4-trifluoromethyl coumarin (AFC) was purchased from Enzyme Systems Products (Livermore, CA). $\epsilon$-Aminon-caproic acid (EACA) was purchased from Calbiochem-Behring Corp. (La Jolla, CA). Type VII calf mucosal alkaline phosphatase, p-nitrophenyl phosphate, and soybean trypsin inhibitor were purchased from Sigma Chemical Co. (St. Louis, MO). All reagents were of analytical grade.

Purified proteins. Purified human TSP was prepared as described previously (17) by a modification of the method of Lawler et al. (1). 4 to $8 \mathrm{U}$ of fresh human platelets were washed and the TSP was isolated from the thrombin-stimulated releasate by Sepharose 4B gel exclusion chromatography followed by heparin Sepharose affinity chromatography. The TSP was $95 \%$ pure by sodium dodecyl sulfate-polyacrylamide gel electrophoresis (SDS-PAGE) (17). Purified human glu-Plg was isolated by lysine affinity chromatography (20) followed by gel filtration and was determined to be free of HRGP and fibrinogen by an ELISA specific for these proteins. For the fibrin plate studies, purified human plasminogen (IMCO, Stockholm) was purchased from Mico, USA, New York and was free of TPA activity as determined by the ${ }^{125}$ Ifibrin plate assay. This preparation was $>95 \%$ pure by SDS-PAGE and consisted of only the glu form of Plg. Authentic glu and lys Plg were kindly supplied by Dr. F. J. Castellino (University of Notre Dame, IN) and were used as standards for the SDS-PAGE. Purified human plasmin was obtained by activation of purified Plg with insolubilized urokinase, as described previously (21), and stored at $-70^{\circ} \mathrm{C}$ in $50 \%$ glycerol. Antithrombin III, albumin, gamma-globulin, Factor VIIIrelated antigen (VIIIR:Ag), $\alpha_{2}$-plasmin inhibitor, platelet glycoproteins IIb and IIla, complement components $\left(\mathrm{C}_{1 \mathrm{q}}, \mathrm{C}_{3}, \mathrm{C}_{4}, \mathrm{C}_{5}\right)$, high molecular weight kininogen, coagulation Factors $\mathrm{X}$ and XII, and fibronectin, which were used as control proteins for the ELISA and fibrin plate studies, were obtained and purified as described in detail previously $(14,17)$. Plg-free human fibrinogen was obtained from IMCO, purified bovine fibrinogen from Calbiochem-Behring Corp. Human melanoma cell line TPA $(70,000 \mathrm{IU} / \mathrm{mg})$ was a generous gift of Dr. Desiré Collen, University of Leuven, Belgium.

Antisera. Antisera to purified Plg and TSP were raised in rabbits by standard techniques (22). Anti-Plg did not react as determined by ELISA with purified human fibrinogen, IgG, albumin, fibronectin, TSP, or Factor VIIIR:Ag. Preparation and monospecificity of other antisera has been documented in detail previously $(14,17)$. Anti-TSP did not react with Plg as determined by ELISA.

Radioisotope labeling. Purified proteins were labeled with ${ }^{125} \mathrm{I}$ by the modified chloramine-T method (23). For the rocket immunoelectrophoresis studies, specific activity of the $\mathrm{Plg}$ was $3.7 \times 10^{5} \mathrm{cpm} / \mu \mathrm{g}$, and specific activity of the TSP was $8.2 \times 10^{4} \mathrm{cpm} / \mu \mathrm{g}$. For the fibrin plate studies the specific activity of the fibrinogen was $2 \times 10^{5} \mathrm{cpm} /$ pmol.

Reductive alkylation of thrombospondin. A sample of purified TSP was reduced in 3\% 2-mercaptoethanol for $3 \mathrm{~h}$ at room temperature and followed by alkylation in $0.25 \mathrm{M}$ iodoacetamide, $\mathrm{pH}$ 8.0. Complete reduction was confirmed by SDS-PAGE of this material, which revealed a single band of $M_{r} 180,000$, identical to that of TSP monomer.

Rocket immunoelectrophoresis. Agarose stocks were prepared by melting electrophoresis grade agarose in $0.05 \mathrm{M}$ phosphate buffer, $\mathrm{pH}$ 7.4 , at a concentration of $1 \%$. The melted agarose was cooled to $45^{\circ} \mathrm{C}$ and mixed with the indicated volume of prewarmed antiserum. 3 to 5 $\mathrm{ml}$ of antibody-agarose mixture was layered onto glass microscope slides. Antigen samples were applied into 4-mm diam wells and the individual slides were subjected to $50 \mathrm{~V}$ and $3 \mathrm{~mA}$ for $20 \mathrm{~h}$ at $22^{\circ} \mathrm{C}$. After electrophoresis the slides were washed exhaustively with saline containing $0.1 \%$ azide and followed by a 30-min distilled-water wash, dried, and stained with $1 \%$ amido black in $40 \%$ ethanol- $10 \%$ acetic acid and destained in $90 \%$ methanol-5\% acetic acid.

Fibrin-agar indicator gels. The fibrin-agar indicator gels were prepared by the method of Reich (24) with the following solutions: $(a)$ $2.5 \%$ agar in water boiled for $10 \mathrm{~min}$ before use and kept at $45^{\circ} \mathrm{C} ;(b)$ phosphate-buffered saline (PBS) supplemented with thrombin $(0.2$ $\mathrm{U} / \mathrm{ml}$ ) and TPA $(0.2 \mathrm{U} / \mathrm{ml})$; and $(c)$ PBS with Plg-free fibrinogen (10 $\mathrm{mg} / \mathrm{ml})$. Solution $a(3.2 \mathrm{ml})$ was added to solutions $b(1.9 \mathrm{ml})$ and $c$ $(1.3 \mathrm{ml})$, and the mixture was transferred to prewarmed templates to form a gel free of bubbles. Gels for rocket immunoelectrophoreses were prepared as described above, placed carefully on top of the indicator gel, and sealed in plastic wrap for $18 \mathrm{~h}$ in a humid chamber at $37^{\circ} \mathrm{C}$. Lysis zones were identified as clear areas in the cloudy background of the unlysed fibrin. The upper immunoelectrophoresis gel was removed and the underlying fibrin layer was stained for 10 min with $0.5 \%$ amido black in $40 \%$ ethanol- $10 \%$ acetic acid and destained in $90 \%$ methanol-5\% acetic acid. The upper gel layer was also stained to determine the completeness of the transfer of the Plgcontaining immunoprecipitate.

ELISA. The assay was performed according to the method of Voller et al. (25) as previously described $(14,17)$. Microtitration plates were coated with $0.2 \mathrm{ml}$ purified TSP, $4 \mu \mathrm{g} / \mathrm{ml}$, in bicarbonate coating

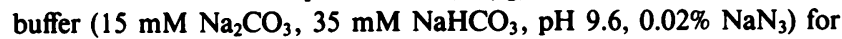
$3 \mathrm{~h}$ at $37^{\circ} \mathrm{C}$. The wells were washed three times with Tris-Tween buffer (10 mM Tris- $\mathrm{HCl}, 0.15 \mathrm{M} \mathrm{NaCl}, 0.05 \%$ Tween $20, \mathrm{pH} 7.4$ ), and then purified Plg was added in duplicate (diluted in the same buffer) for 18 $\mathrm{h}$ at $4^{\circ} \mathrm{C}$. After washing to remove unbound $\mathrm{Plg}$, alkaline phosphataseconjugated anti-Plg $\mathrm{F}\left(\mathrm{ab}^{\prime}\right)_{2}$ prepared as previously described (21) at 1:1,600 dilution was added for $3 \mathrm{~h}$ at $22^{\circ} \mathrm{C}$. After washing, the substrate p-nitrophenyl phosphate was added and color development was followed by repeated readings in a photometer (Titertek Multiskan; Flow Laboratories Inc.). The formation of complex was expressed as the enzymatic activity of the bound alkaline phosphatase $\left(\triangle \mathrm{A} 405 \mathrm{~min}^{-1}\right)$.

Fluorometric plasmin assay. A fluorometric plasmin substrate, Dval-leu-lys-AFC was added to PBS-Tween buffer containing a mixture of purified plasmin $(64 \mathrm{ng} / \mathrm{ml})$ plus TSP. The final volume was $300 \mu \mathrm{l}$ and contained $33 \mathrm{ng}$ substrate and the following molar ratios of TSP/ plasmin: $0: 1 ; 1: 1 ; 49: 1$; and 98:1. Substrate hydrolysis was monitored in a spectrofluorometer (Perkin-Elmer Corp., Instrument Div., Norwalk, CT) at slit width $10 \mu \mathrm{m}$, excitation $400 \mathrm{~nm}$, and emission $505 \mathrm{~nm}$.

Preparation of ${ }^{125} I$-fibrin plates. ${ }^{125} \mathrm{I}$-fibrin plates were prepared by the method of Unkeless et al. (26). To each well of a Linbro tissue culture plate was added $200 \mu$ l of a solution containing 20 pmol ${ }^{125} \mathrm{I}$ - 
labeled bovine Plg-free fibrinogen with specific radioactivity of $\sim 10^{5}$ $\mathrm{cpm} / \mathrm{pmol}$. The wells were then air dried at $37^{\circ} \mathrm{C}$ for $15 \mathrm{~h}$, clotted with thrombin ( $200 \mu \mathrm{l} /$ well of a solution containing $0.04 \mu \mathrm{g} / \mathrm{ml})$, and extensively washed. Plates were used within $10 \mathrm{~d}$ of preparation and washed three times with buffer before use.

Digestion of ${ }^{125}$ I-fibrin films by plasmin or by Plg activated with $T P A$. Purified human plasmin $(0.1$ to $1.0 \mathrm{nM})$ in $200 \mu$ l Tris-saline buffer (20 mM Tris- $\mathrm{HCl}, 0.15 \mathrm{M} \mathrm{NaCl}, \mathrm{pH} 7.4)$ containing $0.25 \%$ gelatin and $0.006 \%$ Tween 80 was added in duplicate to wells of ${ }^{125} \mathrm{I}$ fibrin coated plates. These were gently rocked at $37^{\circ} \mathrm{C}$ and aliquots were removed at specific time intervals and counted to quantify cumulative release of ${ }^{125} \mathrm{I}$-fibrin degradation products.

Purified human Plg (100 to $800 \mathrm{nM}$ ) in $190 \mu$ l Tris-saline buffer containing $0.25 \%$ gelatin, $0.006 \%$ Tween 80 , and $2.0 \mathrm{mM} \mathrm{CaCl}_{2}$ was added in duplicate to wells of ${ }^{125} \mathrm{I}$-fibrin coated plates, which were gently rocked at $37^{\circ} \mathrm{C} .10 \mu \mathrm{l}$ of TPA (final concentration, $0.24 \mathrm{U} / \mathrm{ml}$ ) was then added to the wells and $10-\mu l$ aliquots were taken at intervals and counted.

The influence of TSP on the above reaction(s) was studied by incubating Plg or plasmin in buffer as above with TSP (0-200 nM) for $\mathrm{l} \mathrm{h}$ at room temperature before addition to the ${ }^{125} \mathrm{I}$-fibrin coated wells. Control studies substituted Factor VIIIR:Ag or fibronectin at $200 \mathrm{nM}$ for TSP.

Kinetics of Plg activation by TPA in the presence of TSP. Plg (125 to $800 \mathrm{nM}$ ) was incubated with TSP (0 to $150 \mathrm{nM})$ for $1 \mathrm{~h}$ at room temperature in Tris-saline buffer containing $0.25 \%$ gelatin, $0.006 \%$ Tween 80 , and $1.5 \mathrm{mM} \mathrm{CaCl}$ before addition to the wells of ${ }^{125} \mathrm{I}$ fibrin plates. The Plg was activated with TPA $(0.24 \mathrm{U} / \mathrm{ml})$ for $30 \mathrm{~min}$ at $37^{\circ} \mathrm{C}$ and followed by the addition of $10 \mu \mathrm{l} \mathrm{EACA}$ (final concentration, $80 \mu \mathrm{M})$ to terminate the $\mathrm{Plg}$ activation. This interval was selected because Hoylaerts et al. (27), using a similar assay, have shown that activation is complete by 20 to $30 \mathrm{~min}$. Our preliminary studies (data not shown) demonstrated $>80 \%$ activation at $30 \mathrm{~min}$, with no inhibition of activity of formed plasmin by this concentration of EACA. The cumulative solubilization of fibrin by the generated plasmin was measured as described above and the initial reaction rate was calculated as the amount of plasmin generated per second. All studies were done in duplicate.

\section{Results}

\section{Demonstration of TSP-Plg complex formation by rocket immunoelectrophoresis}

Radiolabeled Plg mixed with TSP (molar ratio 3:1) and electrophoresed into anti-Plg-containing agar migrated more rapidly than $\mathrm{Plg}$ alone and formed an anodally moving sharp peak, which contained $\mathrm{Plg}$ as detected by immunoprecipitation with monospecific antibody and by autoradiography (Fig. 1, $A$ and $B$ ). To demonstrate that the anodal moving peak contained TSP complexed to the Plg, studies were performed using ${ }^{125} \mathrm{I}$ TSP and unlabeled Plg. The fast moving Plg-containing peak demonstrable in antibody agar was radioactive (Fig. 2, $A$ and $B$ ). Plg mixed with albumin, gamma-globulin, or Factor VIIIR:Ag at similar molar ratios to that employed with TSP (3:1) showed no alteration in mobility by rocket immunoelectrophoresis.

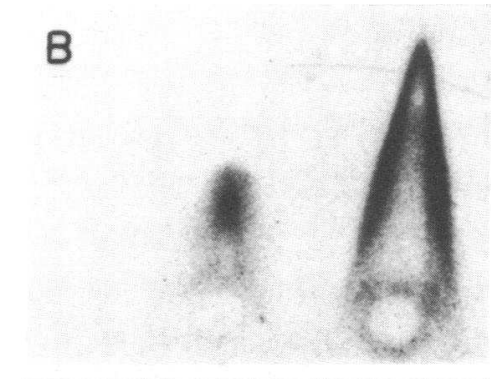

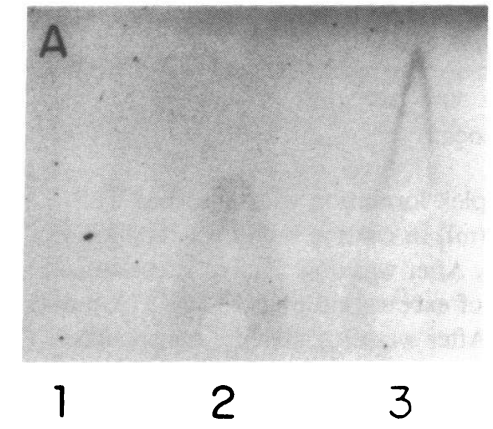

Figure 1. Radioactive PlgTSP rocket immunoelectrophoresis. Well 1, TSP (4.9 $\mu \mathrm{g})$; well 2 , ${ }^{125} \mathrm{I}-\mathrm{Plg}(3.2 \mu \mathrm{g}$, specific activity $9,400 \mathrm{cpm} /$ $\mu \mathrm{g})$; well 3, TSP $(4.9 \mu \mathrm{g})$ plus ${ }^{125} \mathrm{I}-\mathrm{Plg}(3.2 \mu \mathrm{g})$. Proteins were electrophoresed into agarose containing $0.08 \%$ monospecific antiPlg serum. (A) Amido black stain of washed agarose plate. (B) Autoradiograph of $A$.

\section{Demonstration of TSP-Plg complex formation by ELISA}

The ELISA binding assay demonstrated that fluid-phase $\mathrm{Plg}$ bound significantly to purified TSP that was passively adsorbed to wells of a plastic microtitration plate. The extent of binding was quantified by the enzymatic activity of the bound alkaline phosphatase-conjugated anti-Plg $\mathrm{F}\left(\mathrm{ab}^{\prime}\right)_{2}\left(10^{4} \times \Delta \mathrm{A} 405 \mathrm{~min}^{-1}\right)$ (Fig. 3). Complex formation was specific and saturable as demonstrated by complete inhibition of binding in the presence of excess fluid-phase TSP (Fig. 3). Excess fluid-phase albumin did not inhibit complex formation. The apparent $K_{\mathrm{D}}$ for TSPPlg complex formation, approximated from the $50 \%$ binding point on the saturation curve (Fig. 3), was $\sim 35 \mathrm{nM}$. Similarly, the $I_{50}(50 \%$ inhibitory concentration) of fluid phase TSP as a competitive inhibitor of complex formation, determined from a titration experiment over a range of TSP concentrations from 0 to $50 \mathrm{nM}$, was $\sim 18 \mathrm{nM}$, suggesting affinity in fluid phase similar to that in solid phase. No difference in the extent of complex formation was observed when either $1.5 \mathrm{mM}$

Figure 2. Radioactive TSP-Plg rocket immunoelectrophoresis. Well contained nonradioactive $\mathrm{Plg}(3.2 \mu \mathrm{g})$ and ${ }^{125} \mathrm{I}-\mathrm{TSP}(4.9$ $\mu \mathrm{g}$, specific activity $2,700 \mathrm{cpm} /$ $\mu \mathrm{g})$. Proteins were electrophoresed into agarose containing $0.08 \%$ monospecific anti-Plg serum. $(A)$ Amido black stain of washed agarose plate. $(B)$ Autoradiograph of $\boldsymbol{A}$. 


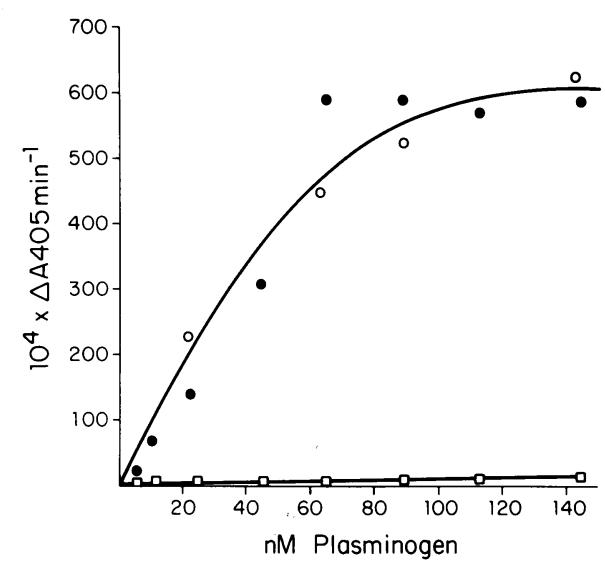

Figure 3. Saturation of Plg complex formation with adsorbed TSP measured by ELISA. TSP $(4 \mu \mathrm{g} / \mathrm{ml})$ in coating buffer was applied to the plastic wells for $3 \mathrm{~h}$ at $37^{\circ} \mathrm{C}$. After washing, $\mathrm{Plg}(\bullet)$, plasmin (O), or plasminogen in the presence of excess fluid phase TSP (23.8 pmol) () was added for $18 \mathrm{~h}$ at $4^{\circ} \mathrm{C}$. After washing, alkaline phosphataseconjugated anti-Plg $\mathrm{F}\left(\mathrm{ab}^{\prime}\right)_{2}$ was added. Curves show complex formation expressed as the enzyme activity of the bound alkaline phosphatase $\left(10^{4} \times \Delta \mathrm{A} 405 \mathrm{~min}^{-1}\right)$.

$\mathrm{CaCl}_{2}$ or $1.0 \mathrm{mM}$ EDTA was included in the buffer with Plg. Reduced alkylated TSP (TSP monomer) adsorbed to microtitration plates also bound Plg in these studies. The extent of binding was equivalent to that of whole TSP, suggesting that one TSP molecule can potentially bind three Plg molecules.

TSP complex formation with plasmin was also detected by ELISA. Plasmin incubated with a fivefold molar excess of soybean trypsin inhibitor to block its active site was added to TSP-coated microtiter plates, and saturable binding was observed (Fig. 3). The protease inhibitor was necessary to prevent proteolytic removal of TSP from the plastic plates by plasmin, since it has been shown that TSP is a substrate of plasmin (28).

Further specificity of complex formation was demonstrated by the inability of fluid-phase Plg to bind other adsorbed proteins. No complex formation was detected with fibronectin, antithrombin III, or Factor VIIIR:Ag (Table I). These proteins were adequately adsorbed to the plastic wells, as shown by binding of monospecific alkaline phosphatase-conjugated IgG and by ${ }^{125} \mathrm{I}$-protein A binding studies (14). We have previously shown that adsorbed TSP did not bind fluid-phase albumin, gamma globulin, $\alpha_{2}$-plasmin inhibitor, antithrombin III, platelet glycoproteins IIb and IIIa, complement components $\mathrm{Cl}_{\mathrm{q}}, \mathrm{C} 3$, C4, C5, high molecular weight kininogen, or coagulation Factors X and XII $(14,17)$.

\section{Influence of Plg lysine binding sites on} TSP-Plg complex formation

With both the rocket immunoelectrophoresis and the ELISA studies, interference with the lysine binding sites of Plg blocked
Table I. Interaction of Plg with Adsorbed Proteins

\begin{tabular}{lc}
\hline Proteins* & $10^{4} \times \Delta \mathrm{A} 405 \mathrm{~min}^{-1}$ \\
\hline TSP & $307.5 \pm 3.6$ \\
AT-III & $17.0 \pm 2.4$ \\
Fibronectin & $21.1 \pm 1.4$ \\
VIIIR:Ag & $19.1 \pm 2.1$ \\
\hline
\end{tabular}

AT-III, antithrombin III.

* Proteins $(4 \mu \mathrm{g} / \mathrm{ml})$ in coating buffer were applied to plastic wells for $18 \mathrm{~h}$ at $4^{\circ} \mathrm{C}$. After washing, $\mathrm{Plg}(4 \mu \mathrm{g} / \mathrm{ml})$ was added and binding was determined as described in Fig. 3.

TSP-Plg complex formation. Incorporation of $10 \mathrm{mM}$ EACA into the anti-Plg antibody agar blocked formation of the rapidly moving anodal peak shown to contain the TSP-Plg complex (Fig. 4). Similarly, EACA added to fluid-phase Plg inhibited TSP-Plg complex formation as detected by ELISA. An inhibition titration over a range of EACA concentration from $10 \mu \mathrm{M}$ to $10 \mathrm{mM}$ demonstrated an $\mathrm{I}_{50}$ of $\sim 200 \mu \mathrm{M}$ (Table II). This is consistent with involvement of the high affinity lysine binding site in the TSP-Plg interaction.

\section{Effect of TSP on digestion of fibrin by}

\section{Plg activated by TPA}

Fibrin agar indicator gels. When rocket immunoelectrophoresis gels prepared as above in anti-Plg-containing agar were overlaid on agar gels containing fibrin and TPA, a clear zone of lysis was easily seen under the immunoprecipitate containing Plg (Fig. $5 B$, well 2). A zone of lysis was also seen under the immunoprecipitate containing the TSP-Plg complex, but the degree of clearing was decreased (Fig. $5 B$, well 3 ), suggesting that TSP interfered with fibrinolysis. To study further the functional implications of the TSP-Plg interaction, $\mathrm{a}^{125} \mathrm{I}$-fibrin plate system was used.

${ }^{125}$ I-fibrin plates. Purified human plasmin at different concentrations added to wells of ${ }^{125}$ I-fibrin-coated plates digested the fibrin, yielding a family of sigmoidal solubilization curves (cumulative release of ${ }^{125} \mathrm{I}$-fibrin degradation products). Each of these curves began at the origin and ended at the same plateau of maximum lysis. The time to reach $50 \%$ of total lysis $\left(\mathbf{S}_{50}\right)$ was an accurate reflection of the amount of plasmin

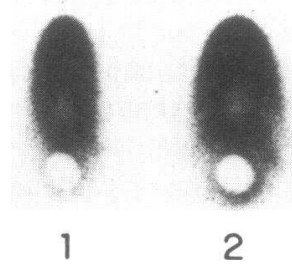

Figure 4. Radioactive TSP-Plg rocket immunoelectrophoresis in presence of EACA. Well 1 contained ${ }^{125} \mathrm{I}-\mathrm{Plg}(3.2$ $\mu \mathrm{g})$ and well 2 contained ${ }^{125} \mathrm{I}-\mathrm{Plg}(3.2$ $\mu \mathrm{g})$ plus TSP $(4.9 \mu \mathrm{g})$. Proteins were electrophoresed in $0.08 \%$ anti-Plg and $10 \mathrm{mM}$ EACA before autoradiography. 
Table II. Influence of Lysine Binding Sites on Complex Formation Between TSP and Plg

\begin{tabular}{lc}
\hline Plg plus & Complex formation \\
\hline Buffer & $100 \%$ \\
EACA $(20 \mu \mathrm{M})$ & $100 \%$ \\
EACA $(100 \mu \mathrm{M})$ & $76.5 \%$ \\
EACA $(500 \mu \mathrm{M})$ & $30.5 \%$ \\
EACA $(1 \mathrm{mM})$ & $23.5 \%$ \\
EACA $(10 \mathrm{mM})$ & $0.6 \%$
\end{tabular}

TSP $(4 \mu \mathrm{g} / \mathrm{ml})$ in coating buffer was applied to plastic wells for $18 \mathrm{~h}$ at $4^{\circ} \mathrm{C}$. After washing, $\mathrm{Plg}(4 \mu \mathrm{g} / \mathrm{ml})$ in buffer or in buffer containing glycine, EACA, or lysine was added. Plg binding was determined as described in Fig. 3.

added to the wells and was linearly related to the log plasmin concentration, as described previously (27). Such a plasmin standard curve was obtained for each set of ${ }^{125}$ I-fibrin plates used.

Similarly, the addition of Plg plus TPA to ${ }^{125}$ I-fibrin-coated plates digested the fibrin and yielded highly reproducible sigmoidal solubilization curves. The $S_{50}$ in these studies reflected the amount of plasmin generated from the Plg by TPA. When Plg was first incubated with TSP before addition to the wells, these curves (and hence $S_{50}$ values) were shifted to the right, reflecting a lower amount of plasmin generated from the same amount of Plg. A representative family of curves for a single $\mathrm{Plg}$ concentration $(200 \mathrm{nM})$ is shown in Fig. $6 \mathrm{~A}$. Fig. $6 \mathrm{~B}$ depicts results from a series of similar experiments done at four different $\mathrm{Plg}$ concentrations, each at five different TSP

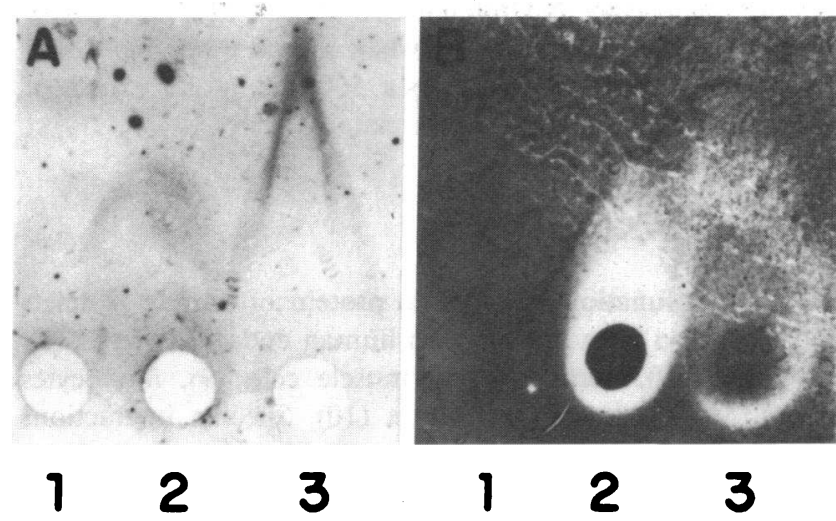

Figure 5. Effect of TSP on digestion of fibrin by Plg activated by TPA demonstrated by a fibrin agar indicator gel assay. $(A)$ Amido black stain of TSP-Plg rocket immunoelectrophoresis in agar containing $0.08 \%$ monospecific anti-Plg serum. Well 1, TSP (4.9 $\mu \mathrm{g})$; well 2 , Plg (3.2 $\mu \mathrm{g})$; and well 3, TSP (4.9 $\mu \mathrm{g})$ plus Plg (3.2 $\mu \mathrm{g})$. (B) Lysis zones (seen as clear area in cloudy background) in fibrin-agar indicator gel containing TPA $(0.2 \mathrm{U} / \mathrm{ml})$ overlaid for $18 \mathrm{~h}$ at $37^{\circ} \mathrm{C}$.
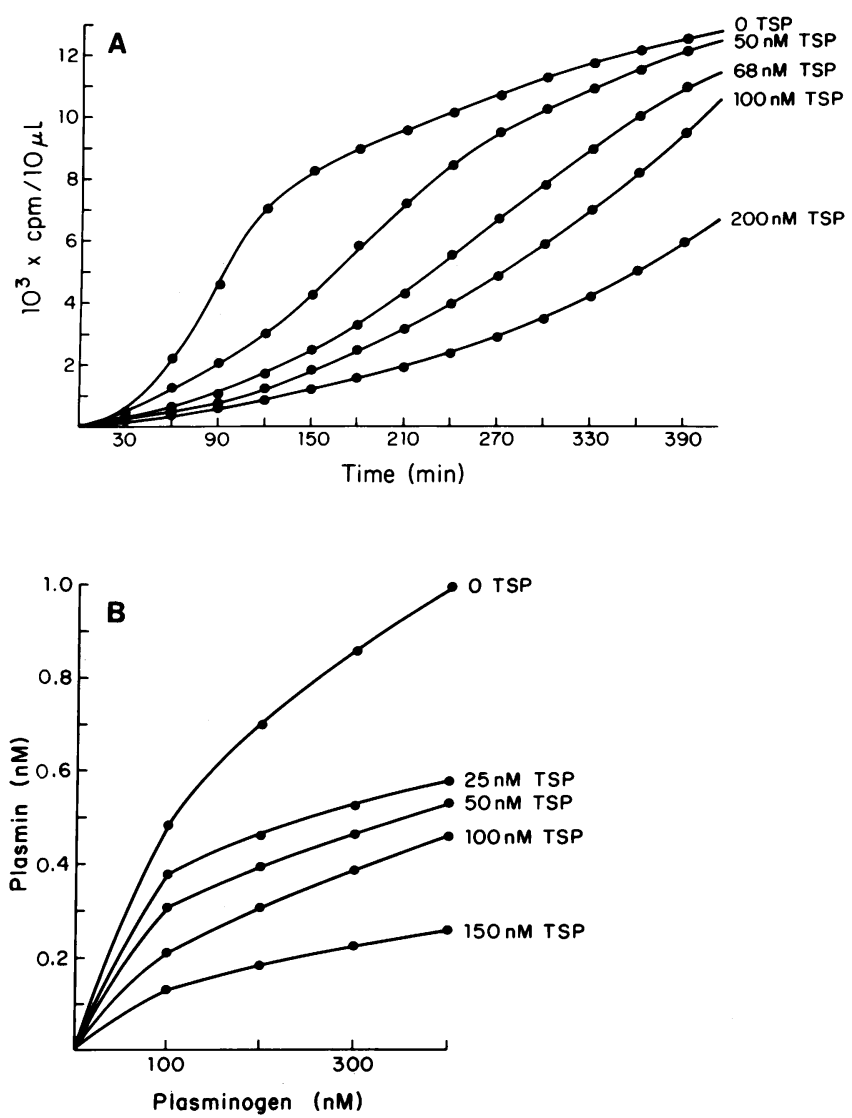

Figure 6. Effect of TSP on solubilization of ${ }^{125} \mathrm{I}$-fibrin by Plg activated by TPA. (A) A solution containing Plg $(200 \mathrm{nM}), \mathrm{CaCl}_{2}$ $(2 \mathrm{mM})$, and different amounts of TSP (0-200 nM) was incubated for $1 \mathrm{~h}$ at room temperature and added to ${ }^{125} \mathrm{I}$-fibrin coated wells. TPA (final concentration, $0.24 \mathrm{U} / \mathrm{ml}$ ) was added to the wells at time 0 and aliquots were taken at timed intervals to quantify release of ${ }^{125}$ I-fibrin degradation products. Curves depict cumulative release of radioactivity. (B) Studies similar to that shown in $A$ were done at different $\mathrm{Plg}$ concentrations (100-400 nM) and $1.5 \mathrm{mM} \mathrm{CaCl}_{2}$, and from $S_{50}$ values the amount of plasmin generated was calculated. TSP concentration was varied from 0 to $150 \mathrm{nM}$.

concentrations $(0-150 \mathrm{nM})$. The data are expressed as the amount of plasmin generated (determined from $\mathrm{S}_{\mathbf{5 0}}$ values) under each set of conditions. The family of curves generated demonstrated that at $\sim 60 \mathrm{nM}$ TSP the generation of plasmin is $50 \%$ inhibited $\left(\mathrm{I}_{50}, \sim 60 \mathrm{nM}\right)$. This inhibition was calcium dependent with maximal inhibition at physiological calcium concentrations of 1.5 to $2.0 \mathrm{mM}$. Specificity of the inhibition was shown by the failure of other platelet $\alpha$-granule glycoproteins (fibronectin or Factor VIIIR:Ag) at similar concentrations (up to $200 \mathrm{nM}$ ) to influence solubilization (Fig. 7). A molecular weight of one million was used to calculate Factor VIIIR:Ag concentrations. 


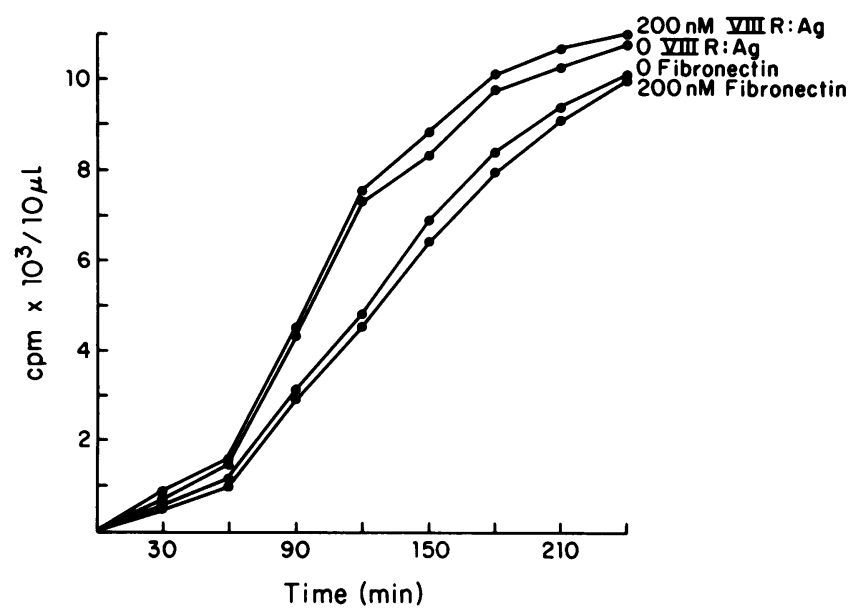

Figure 7. Influence of fibronectin or Factor VIIIR:Ag on solubilization of ${ }^{125}$ I-fibrin by Plg plus TPA. Conditions were similar to those of Fig. $6 \mathrm{~A}$ except that fibronectin or Factor VIIIR:Ag (200 nM) was substituted for TSP.

Influence of TSP on the kinetics of Plg activation by TPA The kinetic analysis of Plg activation by TPA on ${ }^{125}$ I-fibrin plates was determined by measuring the amount of plasmin generated from a 30-min activation of Plg by TPA $(0.24 \mathrm{U} /$ $\mathrm{ml})$ as determined from $S_{50}$ values and a plasmin standard curve. Activation followed Michaelis-Menten kinetics with an apparent $K_{\mathrm{m}}$ of $0.10 \mu \mathrm{M}$ and a catalytic rate constant, $k_{\text {cat }}$, of $7.6 \mathrm{~s}^{-1} \times 10^{3}$ (Table III). The influence of TSP on this reaction was studied and linear plots of $1 / \mathrm{v}$ vs. $1 / \mathrm{Plg}$ were obtained for each TSP concentration using a least squares linear regression analysis (Fig. 8). These lines show a progressive increase in vertical intercept $\left(1 / V_{\max }\right)$ as TSP was increased, with only a corresponding small shift in the horizontal intercept $\left(1 / K_{\mathrm{m}}\right)$, consistent with mixed type inhibition. Although the major component of inhibition was noncompetitive (decrease in $\mathrm{V}_{\max }$ ), there may also be a small competitive effect. The second-order rate constants $k_{\text {cal }} K_{\mathrm{m}}$, a measure of the overall

Table III. Kinetic Parameters of Plg Activation By TPA on Fibrin Plates in the Presence of TSP

\begin{tabular}{rllll}
\hline TSP & $K_{\mathrm{m}}^{*}$ & $V_{\max }$ & $k_{\text {cat }}$ & $k_{\text {cos }} / K_{\mathrm{m}}$ \\
\hline$n m$ & $n m$ & $n m s^{-1} \times 10^{3}$ & $s^{-1} \times 10^{3}$ & $n m s^{-1} \times 10^{6}$ \\
0 & 100 & 0.290 & 7.6 & 76 \\
50 & 120 & 0.160 & 4.2 & 36 \\
100 & 112 & 0.072 & 1.9 & 17 \\
150 & 142 & 0.047 & 1.2 & 9
\end{tabular}

* Kinetic parameters were obtained by use of the ${ }^{125}$ I-fibrin plate assay as detailed in Methods, with the fibrin concentration at $20 \mathrm{pmol} /$ well and TPA concentration at $0.24 \mathrm{U} / \mathrm{ml}$.

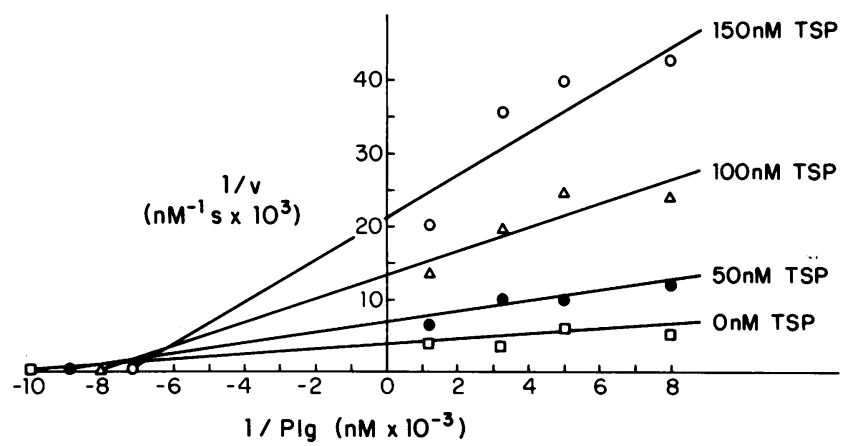

Figure 8. Lineweaver-Burke plot of activation of $\mathrm{Plg}$ on ${ }^{125} \mathrm{I}$-fibrin by TPA in the presence of TSP. A solution containing Plg (125 to 800 $\mathrm{nM}), \mathrm{CaCl}_{2}(1.5 \mathrm{mM})$ and TSP $(0-150 \mathrm{nM})$ was added to ${ }^{125} \mathrm{I}$-fibrin plates and activated by addition of TPA (final concentration, $0.24 \mathrm{U}$ / $\mathrm{ml}$ ). Activation was terminated by the addition of EACA (final concentration, $80 \mu \mathrm{M}$ ) at $30 \mathrm{~min}$. The amount of plasmin generated by the 30 -min activation was calculated from $S_{50}$ values.

catalytic efficiency of Plg activation by TPA, showed that the overall reaction was markedly slowed in the presence of TSP.

\section{TSP influence on plasmin activity}

Using a synthetic tripeptide fluorometric plasmin substrate (Dval-leu-lys-AFC) it was found that TSP did not inhibit plasmin activity in vitro. No difference in substrate hydrolysis as measured in relative fluorometric units was seen when $6.4 \mathrm{ng} /$ $\mathrm{ml}$ plasmin was mixed with buffer alone or with 1:1, 49:1, or 98:1 molar ratios of TSP/plasmin. Incubation of TSP and plasmin for $30 \mathrm{~min}$ before addition of the substrate also had no effect.

Similarly, no inhibition of plasmin activity was seen on a ${ }^{125}$ I-fibrin plate assay. No difference in the rate of solubilization of the fibrin was demonstrated when plasmin was incubated with buffer alone or with up to a 500 -fold molar excess of TSP before addition to the fibrin plate.

\section{Discussion}

TSP, a multifunctional $\alpha$-granule protein of human platelets $(4,5)$, has also been identified in human endothelial cells (7), fibroblasts (10), aortic smooth muscle cells (9), monocytes (11), and the extracellular matrix (10). Specific interactions have been identified with heparin (18), fibrinogen (14), fibronectin, collagen (16), and HRGP (17). These interactions suggest multiple functional roles, for example, in modulating cell-cell communication (12), cell-substratum interactions, platelet aggregation (15), and regulation of thrombotic influences at vessel surfaces.

$\mathrm{Plg}$, the circulating zymogen of the serine protease plasmin, is the major enzyme of the fibrinolytic system (29) and in addition may be important in effecting other proteolytic pro- 
cesses such as inflammation and tumor cell invasion and migration $(24,30)$. In this study we have demonstrated by two independent lines of evidence that purified platelet TSP formed a complex with human Plg. By rocket immunoelectrophoresis it was demonstrated that Plg mixed with TSP when electrophoresed into antibody agar moved more rapidly than $\mathrm{Plg}$ alone and formed an anodally moving sharp peak which contained Plg as well as TSP (Figs. 1 and 2). In addition, an ELISA binding assay, which we have previously used to demonstrate specific TSP interaction with fibrinogen and HRGP $(14,17)$, showed specific and saturable binding of Plg to TSP adsorbed on microtitration plates, with an apparent $K_{\mathrm{D}}$ of 35 nM (Fig. 3).

The binding of Plg and TSP is mediated by the LBS of Plg. Saturation of these sites with $10 \mathrm{mM}$ EACA or lysine completely inhibited complex formation in both ELISA and rocket immunoelectrophoresis systems. The $I_{50}$ of EACA in the competitive inhibition study of $\sim 200 \mu \mathrm{M}$ (Table II) is most consistent with involvement of the high affinity LBS. The protease plasmin that contains the LBS on its A-chain also specifically complexed with TSP (Fig. 3). The active site of the enzyme was apparently not involved in the complex formation, as incubation with soybean trypsin inhibitor did not prevent binding (Fig. 3).

The LBS of Plg are critically important in regulating Plg activation $(31,32)$, and in mediating the interaction of plasmin(ogen) with fibrin(ogen) and $\alpha_{2}$-plasmin inhibitor, as well as with HRGP and the antifibrinolytic amino acids. The kinetics of conversion of Plg to plasmin by TPA are highly unfavorable in the fluid phase. However, during blood coagulation both TPA and Plg bind to fibrin, changing the conformation of the proteins so that rapid activation ensues (27). Since the LBS of Plg appear to mediate complex formation with TSP and since TSP is likely to be present at significant concentrations in the local environment of a clot (via platelet activation and secretion), we have studied the effect of TSP on Plg activation by TPA. A fibrin-agar indicator gel system demonstrated less lysis by the TSP-Plg complex than by equal amounts of Plg alone (Fig. 5), suggesting that the TSP-Plg complex may be a less efficient substrate for TPA than is pure Plg. That this inhibition of lysis was not due to an anti-plasmin effect of TSP was shown by failure of TSP to inhibit plasmin activity both on a ${ }^{125}$ I-fibrin plate assay or in fluid phase using a fluorometric plasmin substrate. In the ${ }^{125}$ I-fibrin plate system, however, TSP significantly inhibited the generation of plasmin activity by TPA from Plg (Fig. 6) with an $I_{50}$ of $\sim 60 \mathrm{nM}$. This inhibition was calcium dependent, being maximal at physiological levels of 1.5 to $2.0 \mathrm{mM}$.

Kinetic studies of $\mathrm{Plg}$ activation on fibrin are complicated since fibrin is both a substrate for the end product of the reaction, plasmin, and a strong positive effector of the reaction (27). Hoylaerts et al., however, have shown that the activation step (i.e., conversion of Plg to plasmin) is much faster than the actual solubilization of the fibrin film, so that by terminating activation with EACA the two processes can be separated in time, allowing measurement of an initial activation rate. Using this method we have demonstrated, in agreement with previously published results (27), that Plg activation follows Michaelis-Menten kinetics and have demonstrated in the present study that TSP acts as a mixed inhibitor of Plg activation, with the major component being noncompetitive; i.e., the $K_{\mathrm{M}}$ was only minimally affected while $V_{\max }$ was considerably slowed (Fig. 8). Plg activation probably proceeds via the sequential formation of a TPA-fibrin-Plg ternary complex (27):

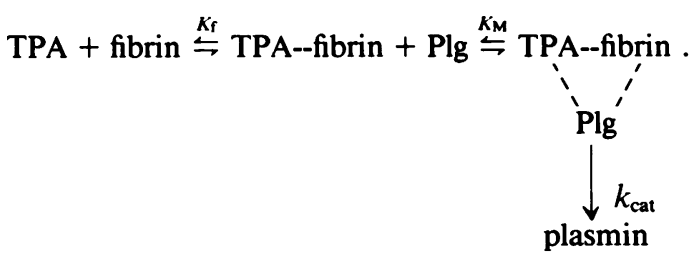

TSP is a noncompetitive inhibitor and thus may independently form another ternary complex with equal affinity for TPA, which is catalytically less active $\left(k_{\text {cat }}^{\prime} \ll k_{\text {cat }}\right)$ :

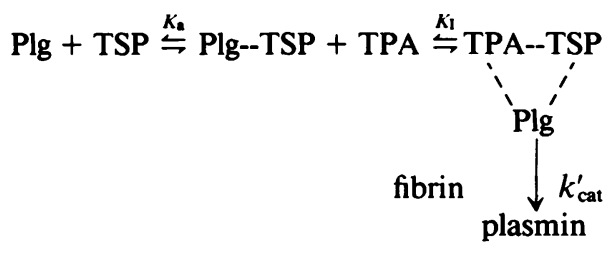

Recent studies using isolated purified constituents strongly suggest that TSP, Plg, and TPA form a ternary complex (Silverstein, R. L., R. Nachman, L. L. K. Leung, and P. C. Harpel, manuscript in preparation). The role of possible binary TSP-TPA complex formation in affecting the inhibition of plasmin generation remains to be determined.

These studies support the hypothesis that TSP acting as a multifunctional regulator in focal areas of active hemostasis and thrombosis could serve as a prothrombotic influence, leading to increased deposition of fibrin. We have previously shown that the interaction of TSP with fibrinogen on the activated platelet surface is an important step in the platelet aggregation process (15) and have recently shown that TSP specifically complexes with HRGP (17), a plasma and platelet $\alpha$-granule protein with high affinity for heparin (18). This interaction may be important in concentrating the heparinneutralizing action of HRGP to the vicinity of a platelet plug. The findings in the present study raise the possibility that by modulating the activation of Plg by TPA, TSP could further enhance fibrin deposition at platelet-blood vessel wall interfaces. It remains to be shown how the interaction of Plg with HRGP (19) affects these interactions.

The full biological significance of the TSP-Plg interaction remains an important subject for future studies. In addition to removal of fibrin from the vascular bed, the Plg activatorplasmin system is important in other physiological and patho- 
logical processes (30), such as inflammation (33), neoplasia (34), and embryogenesis $(35,36,37)$. Through a complex system of controls including the level of tissue production of TPA (38), localized degradation and inactivation of TPA (39, 40 ), inactivation of plasmin by circulating inhibitors (21), and microenvironmental influences on the kinetics of Plg activation, Plg activation may be a general mechanism for generating localized proteolysis in a microenvironment (30). TSP may play an important role in such non-fibrin mediated $\mathrm{Plg}$ activator systems. Although it circulates at very low levels, TSP may be present in significant concentrations in the microenvironment where Plg activation occurs, e.g., by platelet degranulation, as can occur at sites of inflammation or tumor cell metastasis, as part of the normal connective tissue or endothelial extracellular matrix or in association with cellular surfaces. Since TSP is functionally immobilized (like fibrin), it may modulate the kinetics of TPA-induced plasminogen activation at extravascular sites.

\section{Acknowledgments}

We thank Miss Barbara Ferris for excellent technical assistance.

This work was supported by grant HL18828 (Specialized Center of Research in Thrombosis) from the National Institutes of Health.

\section{References}

1. Lawler, J. W., H. S. Slayter, and J. E. Coligan. 1978. Isolation and characterization of a high molecular weight glycoprotein from human blood platelets. J. Biol. Chem. 283:8609-8616.

2. Baenziger, N. L., G. N. Brodie, and P. W. Majerus. 1971. Isolation and properties of a thrombin sensitive protein of human platelets. Proc. Natl. Acad. Sci. USA. 68:240-243.

3. Margossian, S. S., J. W. Lawler, and H. S. Slayter. 1981. Physical characterization of platelet thrombospondin. J. Biol. Chem. 256:74957500.

4. Hagen, I. 1975. Effects of thrombin on washed human platelets: changes in subcellular fractions. Biochim. Biophys. Acta. 392:242-254.

5. Gerrard, J. M., D. R. Phillips, G. H. R. Rao, E. F. Plow, D. A. Walz, R. Ross, L. A. Harker, and J. G. White. 1980. Biochemical studies of two patients with the gray platelet syndrome. Selective deficiency of platelet alpha granules. J. Clin. Invest. 66:102-109.

6. Phillips, D. R., L. K. Jennings, and H. R. Prasana. 1980. Calcium mediated association of glycoprotein-G (thrombin-sensitive protein, thrombospondin) with human platelets. J. Biol. Chem. 255: 11629-11632.

7. Mosher, D. F., M. J. Doyle, and E. A. Jaffe. 1982. Synthesis and secretion of thrombospondin by cultured human endothelial cells. J. Cell Biol. 93:343-348.

8. Saglio, S. D., and H. S. Slayter. 1982. Use of a radioimmunoassay to quantify thrombospondin. Blood. 59:162-166.

9. McPherson, J., H. Sage, and P. Bornstein. 1981. Isolation and characterization of a glycoprotein secreted by aortic endothelial cells in culture: apparent identity with platelet thrombospondin. J. Biol. Chem. 256:11330-11336.

10. Jaffe, E. A., J. T. Ruggiero, L. L. K. Leung, M. J. Doyle, P. J.
McKeown-Longo, and D. F. Mosher. 1983. Cultured human fibroblasts synthesize and secrete thrombospondin and incorporate it into the extracellular matrix. Proc. Natl. Acad. Sci. USA. 80:998-1002.

11. Schwartz, B. S., M. J. Doyle, L. L. Westrick, and D. F. Mosher. 1983. Human peripheral blood monocytes synthesize and secrete thrombospondin. Blood. 62(Suppl. 1):87a. (Abstr.)

12. Jaffe, E. A., L. L. K. Leung, R. L. Nachman, R. I. Levin, and D. F. Mosher. 1982. Thrombospondin is the endogenous lectin of human platelets. Nature (Lond.). 295:246-248.

13. Gartner, T. K., M. J. Doyle, and D. F. Mosher. 1983. AntiTSP serum inhibits the endogenous lectin activity of A23187 activated and gamma-thrombin activated human platelets. Thromb. Haemostas. 50:124. (Abstr.)

14. Leung, L. L. K., and R. L. Nachman. 1982. Complex formation of platelet thrombospondin with fibrinogen. J. Clin. Invest. 70:542549.

15. Leung, L. L. K. 1984. The role of thrombospondin in platelet aggregation. J. Clin. Invest. 74:1764-1772.

16. Lahav, J., M. A. Schwartz, and R. O. Hynes. 1982. Analysis of platelet adhesion with a radioactive chemical crosslinking reagent: interaction of thrombospondin with fibronectin and collagen. Cell. 31:253-262.

17. Leung, L. L. K., R. L. Nachman, and P. C. Harpel. 1984. Complex formation of platetet thrombospondin with histidine rich glycoprotein. J. Clin. Invest. 73:5-12.

18. Lijnen, H. R., M. Hoylaerts, and D. Collen. 1983. Heparin binding properties of human histidine rich glycoprotein. J. Biol. Chem. 255:3803-3808.

19. Lijnen, H. R., H. Hoylaerts, and D. Collen. 1980. Isolation and characterization of a human plasma protein with high affinity for the lysine binding sites in plasminogen. J. Biol. Chem. 255:1021410222.

20. Deutsch, D. G., and E. T. Mertz. 1970. Plasminogen: purification from human plasma by affinity chromatography. Science (Wash. DC). 170:1095-1096.

21. Harpel, P. C. 1981. $\alpha_{2}$-Plasmin inhibitor and $\alpha_{2}$-macroglobulin complexes in plasma: quantification by an enzyme-linked differential antibody immunosorbent assay. J. Clin. Invest. 68:46-55.

22. Garvey, J. S., N. E. Cremer, and D. H. Sussdorf. 1977. Methods in Immunology. Third ed. W. A. Benjamin, Inc. Reading, MA. 7-39.

23. McConahey, P. J., and F. J. Dixon. 1966. A method of trace iodination of proteins for immunological studies. Int. Arch. Allergy Appl. Immunol. 29:185-189.

24. Reich, E. 1978. Activation of plasminogen: a widespread mechanism for generating localized extracellular proteolysis. In Biological Markers of Neoplasia: Basic and Applied Aspects. R. W. Rudden, editor. Elsevier/North Holland, Amsterdam. 491-500.

25. Voller, A., D. Bidwell, and A. Bartlett. 1976. Microplate enzyme immunoassays for the immunodiagnosis of virus infections. In Manual of Clinical Immunology. N. R. Rose and H. Friedman, editors. American Association of Microbiology, Washington DC. 506512.

26. Unkeless, J. C., A. Tobia, L. Ossowski, J. P. Quigley, D. Rifkin, and E. Reich. 1973. An enzymatic function associated with transformation of fibroblasts by oncogenic viruses. J. Exp. Med. 137:88-111.

27. Hoylaerts, M., D. C. Rijken, H. R. Lijnen, and D. Collen. 1982. Kinetics of the activation of plasminogen by human tissue plasminogen activator: role of fibrin. J. Biol. Chem. 257:2912-2919.

28. Lawler, J. W., and H. S. Slayter. 1981. The release of heparin 
binding peptides from platelet thrombospondin by proteolytic action of thrombin, plasmin and trypsin. Thromb. Res. 22:267-279.

29. Wiman, B. 1978. Biochemistry of plasminogen to plasmin conversion. In Fibrinolysis. Current fundamental and Clinical Aspects. P. J. Gaffrey and S. Balkuv-Ulutin, editors. Academic Press, London. 47-60.

30. Astrup, T. 1975. Cell induced fibrinolysis: a fundamental process. In Proteases and Biological Control. E. Reich, D. B. Rifkin, and E. Shaw, editors. Cold Spring Harbor Laboratory, New York. 343-355.

31. Wiman, B., and P. Waller. 1977. The specific interaction between plasminogen and fibrin: a physiological role of the lysine binding site in plasminogen. Thromb. Res. 10:213-222.

32. Lijnen, H. R., and D. Collen. 1982. Interaction of plasminogen activators and inhibitors with plasminogen and fibrin. Sem. Thromb. Hemostasis. 8:2-10.

33. Unkeless, J. C., S. Gordon, and E. Reich. 1974. Secretion of plasminogen activator by stimulated macrophages. J. Exp. Med. 139:834-850.
34. Wilson, E. L., and E. B. Dowdle. 1978. Secretion of plasminogen activator by normal reactive and neoplastic human tissues in vitro. Int. J. Cancer. 22:390-399.

35. Strickland, S., and W. H. Beers. 1976. Studies on the role of the plasminogen activator in ovulation. J. Biol. Chem. 251:5694-5702.

36. Strickland, S., E. Reich, and M. I. Sherman. 1976. Plasminogen activator in early embryogenesis: enzyme production by trophoblast and parietal endoderm. Cell. 9:231-240.

37. Moonen, G., M. P. Grau-Wagemans, and I. Selak. 1982. Plasminogen activator system and neuronal migration. Nature (Lond.). 298:753-755.

38. Loskutoff, D. J., and T. S. Eddington. 1977. Synthesis of a fibrinolytic activator and an inhibitor by endothelial cells. Proc. Natl. Acad. Sci. USA. 74:3963-3967.

39. Hoal, H. G., E. L. Wilson, and E. B. Dowdle. 1983. The regulation of tissue plasminogen activator activity by human fibroblasts. Cell. 34:273-279.

40. Chmieleweska, J., M. Ranby, and B. Wiman. 1983. Evidence for a rapid inhibitor to TPA in plasma. Thromb. Res. 31:427-436. 